\title{
Effect of Supercritical Fluids on Field Emission from Carbon Nanotubes
}

\author{
P. T. Liu ${ }^{1}$,C. T. Tsai ${ }^{2}$, K. T. Kin, ${ }^{3}$ P. L. Chang ${ }^{3}$, C. M. Chen ${ }^{3}$, H. F. Cheng ${ }^{3}$, \\ T. C. Chang ${ }^{4}$ \\ ${ }^{1}$ Department of Photonics and Display Institute, National Chiao Tung University, Taiwan, R.O.C. \\ ${ }^{2}$ Institute of Electronics Engineering, National Tsing Hua University, Taiwan, R.O.C. \\ ${ }^{3}$ Industrial Technology Research Institute-Energy \&Resources Laboratories, 195, Sec. 4, Chung Hsing Rd., Chutung, Hsinchu, \\ Taiwan 310, R.O.C. \\ ${ }^{4}$ Department of Physics and Institute of Electro-Optical Engineering, National Sun Yat-set University, Taiwan, R.O.C.
}

\begin{abstract}
This paper proposes a novel method to enhance the emission characteristics of carbon nanotubes (CNTs). It is extremely possible for CNTs to adsorb moisture and other contaminants during the fabrication processes, leading to the degraded field emission characteristics. In this work, CNT emitters are activated with commonly used heating process and supercritical carbon dioxide $\left(\mathrm{SCCO}_{2}\right)$ fluids technology for removing adsorbed residue moisture. Experimental results have demonstrated that the electrical stability and field emission enhancement of CNT emitters are effectively achieved by the $\mathrm{SCCO}_{2}$ fluids treatment compared to the heating process, due to the minimization of residuary moisture in CNTs.
\end{abstract}

\section{INTRODUCTION}

In recent years, carbon nanotubes (CNTs) have been employed in electron field emitters and extraordinarily suitable materials for field emission display (FED) applications because of their high mechanical strength and chemical stability coupled with very high aspect ratios leading to extremely strong local fields [1-4]. For achieving better emission characteristic, the CNTs need to be produced with free of contamination and minimized moisture adsorption. During the fabrication process of CNTs, it is extremely possible for CNTs to adsorb moisture and other contaminants, leading to degrade field emission characteristics and electrical instability. Experimental work that really focused on the study of moisture adsorption effect has been greatly scanty so far, and few methods have been reported for minimizing residual moisture and other contaminants in the nano-structure CNTs. Therefore, in this work the influence of residual moisture on the field emission characteristics of CNTs will be investigated first. In addition, the application of supercritical carbon dioxide $\left(\mathrm{SCCO}_{2}\right)$ fluids will be proposed to activate $\mathrm{CNT}$ emitters, minimizing residual moisture and contaminants uptake. The $\mathrm{CO}_{2}$-based process is attractive because of its environmental compatibility, nontoxic, nonflammable and unreactive under most conditions [5]. The $\mathrm{SCCO}_{2}$ fluids are similar to non-polar liquid $\mathrm{CO}_{2}$ since it could dissolve non-polar solvent and has good transport property to remove contaminants. Besides, it possesses gas-like properties of diffusivity and viscosity that allow it to carry solvents through the narrow spaces between micro- and nano-structure surfaces, without damage to the structure [6]. Also, the extremely low surface tension of $\mathrm{SCCO}_{2}$ fluids can account for its negligible effect (i.e. extremely low damage) on the morphology and microstructures [7-9]. In this study the field emission characteristics, material analysis and electrical stability of CNT emitters will be discussed to exhibit the activation efficiency of the supercritical $\mathrm{CO}_{2}$ fluids technology.

\section{ПI. EXPERIMENTAL PROCEDURES}

CNTs were generally fabricated by several processing techniques, including arc-discharge, laser ablation and chemical vapor deposition (CVD). In this study, the raw material of multi-walled carbon nanotubes was synthesized by arc-discharge. The normal CNT-FED diodes were fabricated by screen printing processes $[10,11]$. First of all, a cathode pattern coated on a glass substrate by screen-printing a conductive slurry containing silver (Ag) through a patterned screen was carried out. Thereafter, a CNT layer was attached thereon by screen-printing a CNT paste through a mesh pattern screen to form CNT emitters. The CNT paste consisted of organic bonding agent, resin, silver powder, and carbon nano-tubes. After that the substrate was soft-baked by an oven at $150^{\circ} \mathrm{C}$ to remove volatile organic solvent. A higher temperature sintering process at $400^{\circ} \mathrm{C}$ for 20 min was then carried out to solidify the CNTs on and well electric coupled with the Ag cathode pattern.

For various CNT applications, it is extremely possible for CNTs suffered from wet liquid environment during different manufacture processes. In order to investigate the influence of moisture uptake on the electron field emission characteristics of CNTs, the screen-printed CNT emitters were then rinsed with deionized (DI) water for $10 \mathrm{~min}$ at $25^{\circ} \mathrm{C}$. A hot-baking step at $100^{\circ} \mathrm{C}$ for $1 \mathrm{hr}$ was first implemented for the initial drying of the DI-water-rinsed CNTs. Subsequently, we employed two kinds of activation methods to improve the field emission characteristics of CNTs. One was a typically used thermal annealing process in a furnace at $200^{\circ} \mathrm{C}$ for $15 \mathrm{~min}$ under $\mathrm{N}_{2}$ atmosphere. 


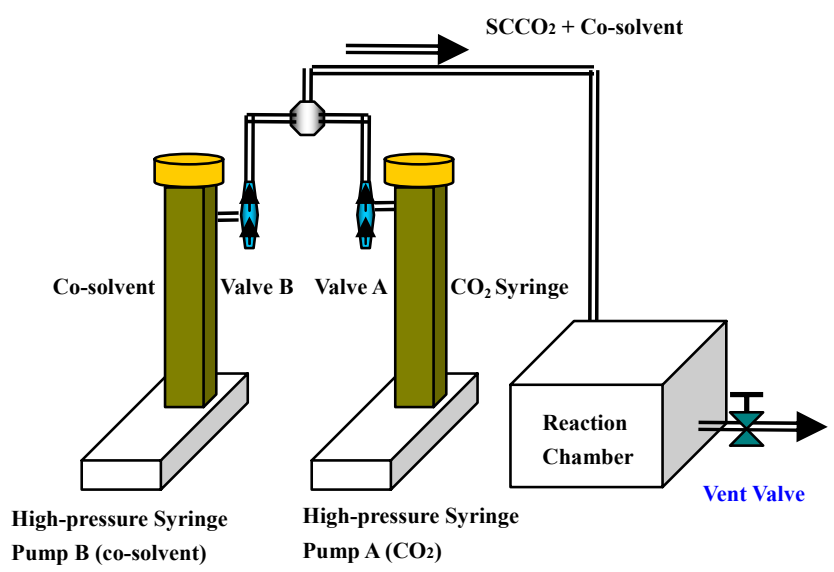

Fig. 1. Schematically showing the configuration of an $\mathrm{SCCO}_{2}$ system.

The second proposed technology was that processing the DI-water-rinsed CNTs at a $\mathrm{SCCO}_{2}$ system for only $5 \mathrm{~min}$ to minimize residual moisture. Moreover, a chemical additive, propyl alcohol, was studied to incorporate into $\mathrm{SCCO}_{2}$ fluids for enhancing the CNT activation efficiency.

Fig. 1 shows basic components of an $\mathrm{SCCO}_{2}$ system. $\mathrm{SCCO}_{2}$ was compressed under 1100 3000 psi, mixed with $0 \sim 7$ vol.\% propyl alcohol and heating batch processing chamber at $50^{\circ} \mathrm{C}$. The batch processing chamber included an impeller for turbulence. Besides, $\mathrm{SCCO}_{2}$ fluids carrying contaminants was bled off to a separator and decompressed to remove them, and then $\mathrm{CO}_{2}$ may be chilled for reuse. After different activating processes, the material analysis was characterized with thermal desorption spectroscopy (TDS). The field emission characteristic and stability of CNT were measured in a vacuum chamber with $5 \times 10^{-6}$ Torr at room temperature. The measured field emission area was $1 \mathrm{~cm}^{2}$ with the parallel-plate geometry, and emission current was characterized with Keithley 237 measurement instrument in the range of $0-1100 \mathrm{~V}$ by a dc mode.

\section{RESULTS AND DISCUSSION}

Fig. 2 shows the field emission current of CNT emitters as a function of the applied electric field under different activation treatments. From the results, it is found among various activation treatments the DI-water-rinsed CNTs after only an initial $100^{\circ} \mathrm{C}$-baking step exhibits the poorest field emission performance (applied at $\sim 5 \mathrm{~V} / \mu \mathrm{m}$, the current density reaching $50 \mu \mathrm{A} / \mathrm{cm}^{2}$ ). The inferior field emission is inferentially due to residual moisture in the $\mathrm{CNT}$ emitters. Moisture adsorption in CNTs would form a blanket of $\mathrm{H}_{2} \mathrm{O}$ capping layer. The moisture passivation layer speculatively results in a field emission barrier, thereby causing the degraded filed emission of the CNT emitters. The further improvement in the field emission current (applied at $\sim 4.6 \mathrm{~V} / \mu \mathrm{m}$, the current density reaching $50 \mu \mathrm{A} / \mathrm{cm}^{2}$ ) is observed for the CNT emitters activated by a furnace annealing step at a higher temperature

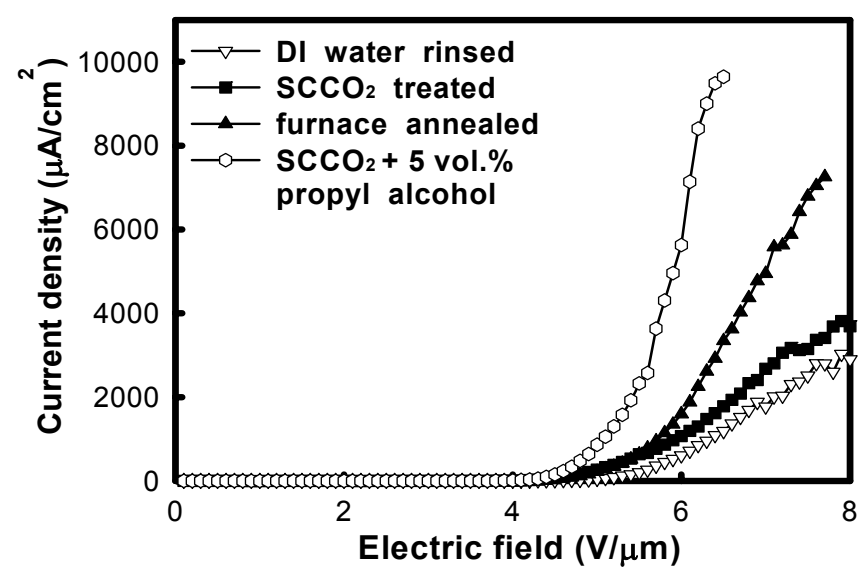

Fig. 2. Field emission current of DI-water-rinsed CNT emitters activated by different treatments, including initial $100^{\circ} \mathrm{C}$-hot-baking (denoted by DI water rinsed), $200^{\circ} \mathrm{C}$-furnace-annealing (denoted by furnace annealed), pure $\mathrm{SCCO}_{2}$ fluid and $\mathrm{SCCO}_{2}$ with 5 vol.\% propyl alcohol.

of $200^{\circ} \mathrm{C}$. This suggests that the activation of DI-water-rinsed CNTs can be enhanced with increasing activation temperatures from $100^{\circ} \mathrm{C}$ to $200^{\circ} \mathrm{C}$, due to the further elimination of residual moisture. The supercritically activated CNT emitters treated with pure $\mathrm{SCCO}_{2}$ fluids, in contrast, is not exhibiting expectedly good field emission properties. In contrast, the enhancement in the field emission current and the decrease in the onset field emission voltage $(\sim 4 \mathrm{~V} / \mu \mathrm{m}$, defined by emission current reaching $\left.50 \mu \mathrm{A} / \mathrm{cm}^{2}\right)$ can be achieved by incorporating a trace of co-solvent propyl alcohol into the $\mathrm{SCCO}_{2}$ fluids.

The field emission current of CNTs was determined by the Fowler-Nordheim (F-N) equation:

$$
I=a V^{2} \exp \left(-b \phi^{3 / 2} / \beta V\right)
$$

where I, V, $\phi, \beta$ are the emission current, applied voltage, work function and field enhancement factor. The larger $\beta$ expresses the larger field concentration, and the lower effective threshold voltage for emission. Therefore, the lower work function and larger field enhancement factor are required for obtaining higher field emission current [12]. The Fowler-Nordheim (F-N) plot and the slope of $\ln \left(\mathrm{J} / \mathrm{E}^{2}\right)$ versus $1 / \mathrm{E}$ plot of the CNT emitters with different activating process are shown in Fig. 3 and Table I, respectively. It can be observed that field emission current corresponds to the F-N tunneling characteristic. A superior emission characteristic will exhibit the larger $\beta$ and lower $\phi$, expectedly showing a relatively gradual slope in the plot of $\ln \left(\mathrm{J} / \mathrm{E}^{2}\right)$ v.s $1 / \mathrm{E}$ by Eqn. (1). Form Table I, we can find that the CNT emitter has the best emission characteristic after activation treatment in $\mathrm{SCCO}_{2}$ with 5 vol.\% of propyl alcohol, while the DI-water-rinsed CNTs after only an initial $100^{\circ} \mathrm{C}$-baking shows the poorest emission characteristic. This also indicates that the absorbed 


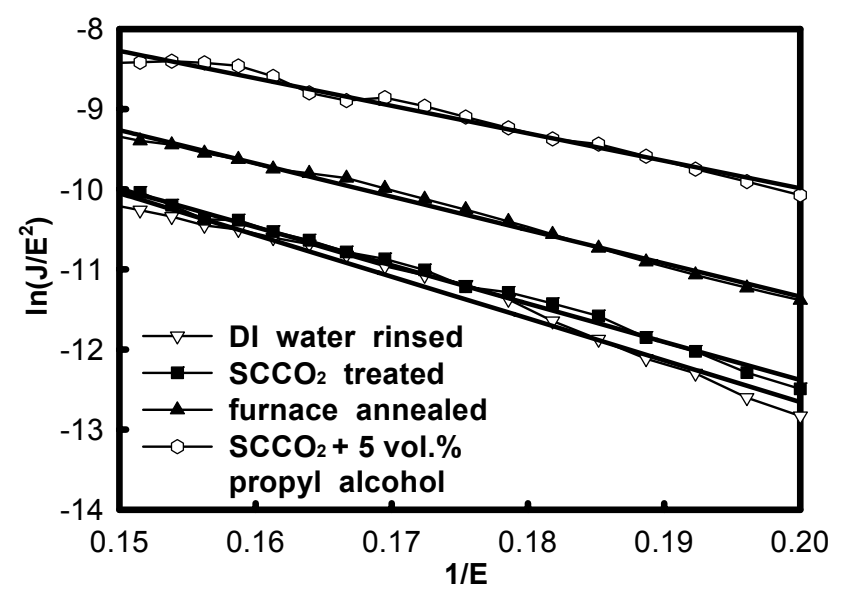

Fig. 3. The $\ln \left(\mathrm{J} / \mathrm{E}^{2}\right)$ vs $1 / \mathrm{E}$ plots of the CNT emitters, where $\mathrm{J}\left(\mathrm{A} / \mathrm{cm}^{2}\right)$ is the current density and $\mathrm{E}(\mathrm{V} / \mu \mathrm{m})$ is the applied electric field.

Table I

The slope of $\ln \left(\mathrm{J} / \mathrm{E}^{2}\right)$ versus $1 / \mathrm{E}$, the efficient emission is obtained by reducing the moisture in carbon nanotubes.

\begin{tabular}{|c|c|c|c|c|}
\hline & DI water rinsed & $\mathrm{SCCO}_{2}$ treated & Furnace annealed & $\begin{array}{c}\mathrm{SCCO}_{2}+5 \text { vol.\% } \\
\text { propyl alcohol }\end{array}$ \\
\hline Slope & -59.785 & -55.127 & -48.12 & -44.879 \\
\hline
\end{tabular}

moisture will seriously degrade the field enhancement factor and cause a barrier to the field emission, leading to an inferior field emission characteristic.

To reasonably verify the inference that the field emission enhancement correlates with the decrease of residual moisture content, it was monitored the evolution of moisture desorption in CNTs after different activation treatments. Thermal desorption spectroscopy (TDS), as shown in Fig. 4, was carried out upon heating these activated CNTs from $80{ }^{\circ} \mathrm{C}$ to $200{ }^{\circ} \mathrm{C}$ at a heating rate of $10^{\circ} \mathrm{C} / \mathrm{s}$ in vacuum $\left(10^{-5} \mathrm{~Pa}\right.$. $)$. In the TDS analysis, $\mathrm{M} / \mathrm{e}$ (mass-to-charge ratio) $=18$ peak that is attributed to $\mathrm{H}_{2} \mathrm{O}$ was monitored to evaluate the residual moisture of the CNTs. The desorption distribution at 100-200 ${ }^{\circ} \mathrm{C}$ is attributed to moisture adsorbed at the surface [13]. From Fig. 4, the highest residual moisture content is observed in the initial $100{ }^{\circ} \mathrm{C}$-hot-baked CNTs, shown inferior electron field emission previously. The residual moisture content is decreased further at a raised annealing temperature $\left(200^{\circ} \mathrm{C}\right)$. Furthermore, the minimized residual moisture content is detected in the $\mathrm{CO}_{2}$ supercritically activated CNT with 5 vol.\% propyl alcohol. This indicates the addition of a trace of co-solvent into the $\mathrm{SCCO}_{2}$ fluid can effectively minimize residual moisture adsorption in the nano-structure CNTs, increasing activation efficiency. The role of co-solvent propyl alcohol can be deduced further as sketched in Fig. 5 .

In this work propyl alcohol acts as a surfactant between hydrophobic supercritical $\mathrm{CO}_{2}$ fluids and polar $\mathrm{H}_{2} \mathrm{O}$ molecules, capable of enhancing the polarization of $\mathrm{SCCO}_{2}$ fluids. The propyl alcohol has a hydrophilic hydroxyl group, easily

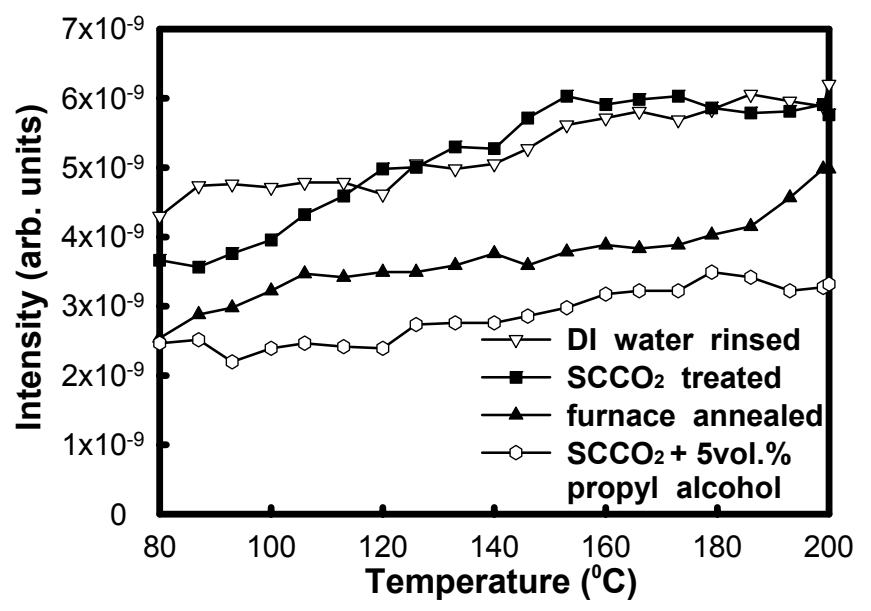

Fig. 4. Thermal desorption spectroscopy (TDS) of DI-water-rinsed CNT emitters with different activation treatments, including initial $100^{\circ} \mathrm{C}$-hot-baking (denoted by DI water rinsed),

$200^{\circ} \mathrm{C}$-furnace-annealing (denoted by furnace annealed), pure $\mathrm{SCCO}_{2}$ fluid and $\mathrm{SCCO}_{2}$ with 5 vol.\% propyl alcohol.

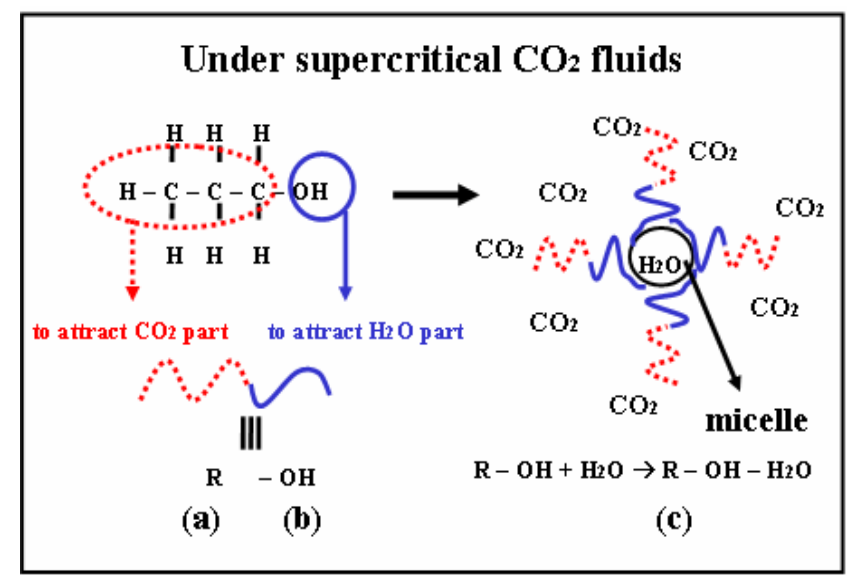

Fig. 5. The formation process of water nanodroplet in a supercritical carbon dioxide solution with the surfactant of propyl alcohol. (a): hydrophobic hydrocarbon group, (b): hydrophilic hydroxyl group, and (c): micelle.

attracting with $\mathrm{H}_{2} \mathrm{O}$ molecules and associates in $\mathrm{SCCO}_{2}$ solution with hydrophobic hydrocarbon group to form a micelle. At certain temperatures, pressures, and co-solvent concentrations, such micelles spontaneously self assemble in $\mathrm{SCCO}_{2}$ solution. Water will be incorporated into the core of the micelle [14], generating a nanodroplet of water in the carbon dioxide solution, and be easily carried away from CNTs by the enhanced polarization $\mathrm{SCCO}_{2}$ fluids. It is critical to enhance the polarization of $\mathrm{SCCO}_{2}$ fluids for minimizing residual moisture in CNTs by micelles self-assembled in the $\mathrm{SCCO}_{2}$ solution. It is thereby required to develop an optimization process condition for maximizing the solubility of co-solvent in the $\mathrm{SCCO}_{2}$ fluids. However, it is challenge due to the fact that supercritical fluids behave different properties under different pressures and temperatures, causing 


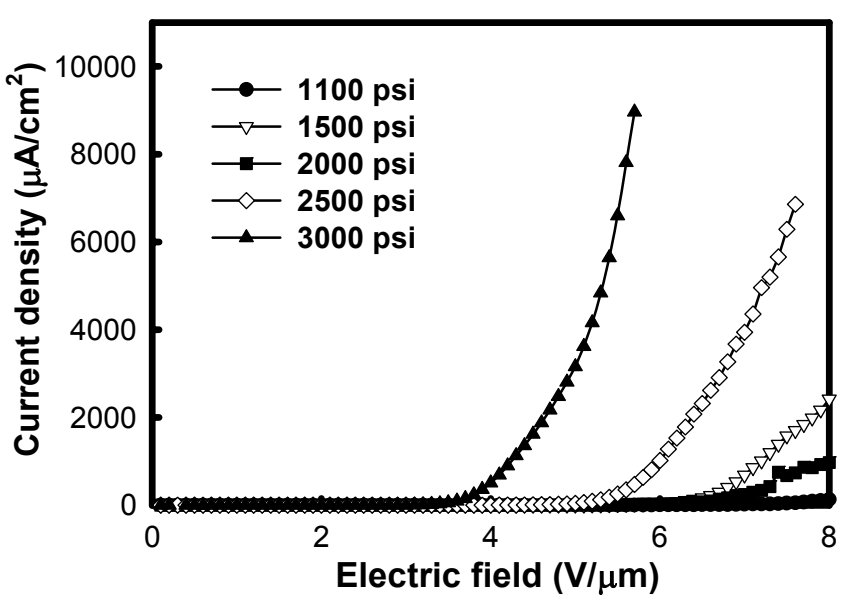

Fig. 6. Field emission characteristics of CNT emitters activated by $\mathrm{SCCO}_{2}$ fluids under different pressure, mixed with 5 vol.\% propyl alcohol and heating at $50^{\circ} \mathrm{C}$

varied solubility of co-solvents [15]. Fig. 6 shows the field emission current of CNT emitters which were activated in $\mathrm{SCCO}_{2}$ fluids at $50^{\circ} \mathrm{C}$ under different pressure, and mixed with 5 vol.\% propyl alcohol. The greatest activation efficiency was obtained when $\mathrm{SCCO}_{2}$ fluids were compressed under 3000psi. This result points out that propyl alcohol has sufficient solubility and efficiently form nanodroplet of water in $\mathrm{SCCO}_{2}$ fluids at $50^{\circ} \mathrm{C}$ under 3000 psi. As shown in Fig. 6, the field emission of CNTs activated with $\mathrm{SCCO}_{2}$ fluids under $1100 \sim 2000$ psi is inferior. Hence, the sufficient solubility of co-solvent propyl alcohol is critical for a successful $\mathrm{SCCO}_{2}$ activating process.

The stability of emission performance was evaluated by monitoring the emission current after a high electric field stress. Fig. 7 shows the field emission current of CNT emitters before and after the high electric field stress of $11 \mathrm{~V} / \mu \mathrm{m}$ for 30 min. In this result, the emission performance of CNTs obviously degrade after the bias stress, resulting in threshold voltage shifts for the DI-water-rinsed and the pure $\mathrm{SCCO}_{2}$-treated $\mathrm{CNTs}$ especially. The electrical instability of bias-stressed CNTs can be attributed to the damage from joule heating and a trace of ion-bombardment damage. As a result of local joule heating along the carbon tube, the emission current may burn the CNTs [16, 17]. Besides, the adsorbed containments could outgas from the CNTs by joule heating, and sequentially be ionized under the stress of high electrical field. These resultant ions easily bombard the carbon nanotubes and cause to the field emission degradation [12]. Therefore, emission current of CNTs decays and higher threshold voltage is required, after the electric field stress for the moisture-absorbed CNT emitters. From Fig. 7, the emission performance of CNTs activated in $\mathrm{SCCO}_{2}$ fluids with 5 vol.\% propyl alcohol is almost intact because of minimizing residue absorbates. Also, it represents the superior electrical stability of CNT emitters, while residuary moisture in CNTs is minimized.

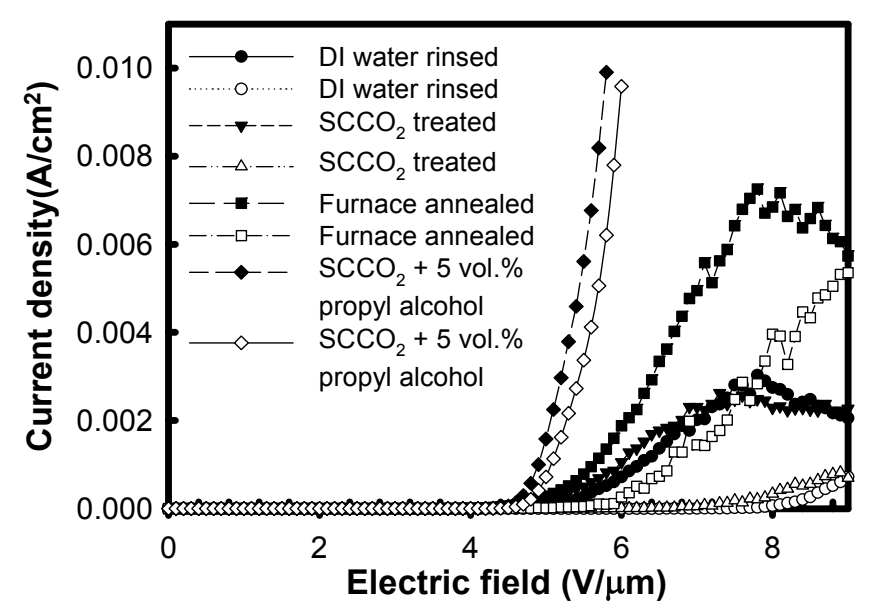

Fig. 7. The field emission characteristics of different activated CNT emitters before(the full dots)/after(the empty dots) high electric field (11 Voltage/ Micro-meter) stressing for 30 minutes.

\section{CONCLUSION}

In this paper, we have experimentally disclosed that the field emission characteristics of CNT emitters will suffer from residue moisture adsorption. The $\mathrm{SCCO}_{2}$ fluids have high mass transfer rates, zero surface tension, and applicable to removing contaminants in microstructure. An optimization activation of CNT emitters has been obtained by the addition of co-solvent propyl alcohol into $\mathrm{SCCO}_{2}$ fluids. Compared to typically used heating process, TDS analysis also demonstrated $\mathrm{SCCO}_{2}$ fluids with propyl alcohol can minimize residual moisture in $\mathrm{CNTs}$. The $\mathrm{SCCO}_{2}$-activated $\mathrm{CNT}$ emitters, thereby, possess superior electron field emission characteristics and electrical stability. Also, it is observed that the solubility of co-solvent in $\mathrm{SCCO}_{2}$ fluids plays a critical role in the activation efficiency. Experimental results suggest the $\mathrm{SCCO}_{2}$ technology will be promising for the activation of CNT emitters and applicable in a variety of industrial processes, due to $\mathrm{CO}_{2}$ being inert, nontoxic, abundantly available at low cost, and environmentally benign.

\section{ACKNOWLEDGEMENT}

This work was performed at Industrial Technology Research Institute-Energy \& Resources Laboratories and National Nano Device Laboratories, Taiwan, R.O.C. The authors would like to acknowledge the financial support of the National Science Council (NSC) under Contract No, NSC 93-2218-E-009-067.

\section{REFERENCE}

[1] T. W. Ebbesen and P. M. Ajayan, "Large-scale synthesis of carbon nanotubes” , Nature (London), vol.358, pp.220-222 (1992).

[2] S. T. Purcell, P. Vincent, C. Journet and V. Thien Binh, "Stable Heating of Individual Multiwall Carbon Nanotubes to $2000 \mathrm{~K}$ Induced by the Field-Emission Current" , Phys. Rev. Letters, vol.88, 105502 (2002). 
[3] S. C. Kung, K. C. Hwang, I. Nan Lin, "Oxygen and ozone oxidation-enhanced field emission of carbon nanotubes” , Appl. Phys. Letters, vol.80, pp.4819-4821 (2002).

[4] W. I. Milne, K. B. K. Teo, G. A. J. Amaratunga, P. Legagneux, L. Gangloff, J. P. Schnell, V. Semet, V. T. Binh and O. Groening, "Carbon nanotubes as field emission sources" , J. Mater. Chem., vol.14, pp.933-943 (2004).

[5] E. J. Beckman, "Green chemical processing using $\mathrm{CO}_{2}$ ", Ind. Eng. Chem Res., vol.42, pp.1598 (2003).

[6] G. L. Weibel, C. K. Ober, "An overview of supercritical $\mathrm{CO}_{2}$ applications in microelectronics processing", Microelectron. Eng., vol.65, pp.145-152 (2003).

[7] H. Namatsu, "Supercritical drying for water-rinsed resist systems", $J$. Vac. Sci. Technol. B., vol.18, pp.3308-3312 (2000).

[8] D. J. Mount, L. B. Rothman, R. J. Robey, M. K. Ali, "The technology behind cleaning with supercritical fluids", Solid State Technology, vol.7, pp.103 (2002).

[9] J. W. King, L. L. Williams, "Utilization of critical fluids in processing semiconductors and their related materials", Current Opinion in Solid State and Materials Sci., vol.7, pp.413-424 (2003)

[10] W. B. Choi, D. S. Chung, J. H. Kang, H. Y. Kim, Y. W. Jin, I. T. Han, Y. H. Lee, J. E. Jung, N. S. Lee, G. S. Park, J. M. Kim, "Fully sealed, high-brightness carbon-nanotube field-emission display”, Appl. Phys. Lett., vol.75, pp.3129-3131 (1999).

[11] J. L. Kwo, M. Yokoyama, W. C. Wang, F. Y. Chuang, I. N. Lin, "Characteristics of flat panel display using carbon nanotubes as electron emitters" ,Diamond Relat. Mater., vol.9, pp.1270-1274 (2000).

[12] Yuan Cheng and Otto Zhou, "Electron field emission from carbon nanotubes” , Comptes Rendus Physique, vol.4, pp. 1021-1033 (2003).

[13] E. Kondoh, M. R. Baklanov, H. Bender, K. Maex, "Structural Change in Porous Silica Thin Film after Plasma Treatment”, Electrochemical and Solid-State Lett., vol.1, pp.224-226 (1998).

[14] M. Z. Yates, D. L. Apodaca, M. L. Campbell, E. R. Birnbaum, T. M. McCleskey, " Micelle Formation and Surface Interactions in Supercritical $\mathrm{CO}_{2}$. Fundamental Studies for the Extraction of Actinides from Contaminated Surfaces” , J. Chem. Comm., vol.1, pp.25 (2001).

[15] Kim, S. and Johnston, K. P., "Supercritical Fluids", T. G. Squires and M. E. Paulaitis, Eds., ACS Symposium Series, vol.329, pp.14 (1987)

[16] S.T. Purcell, P. Vincent, C. Journet, V.T. Binh, "Hot nanotubes: Stable heating of individual multiwall carbon nanotubes to $2000 \mathrm{~K}$ induced by the field-emission current” , Phys. Rev. Lett. vol.8, 105502 (2002).

[17] P. Vincent, S.T. Purcell, C. Journet, V.T. Binh, "Modelization of resistive heating of carbon nanotubes during field emission”, Phys. Rev. $B$, vol.66, 075406 (2002). 